\title{
Optimization of Processing Parameters in ECM of Die Tool Steel Using Nanofluid by Multiobjective Genetic Algorithm
}

\author{
V. Sathiyamoorthy, ${ }^{1}$ T. Sekar, ${ }^{2}$ and N. Elango ${ }^{3}$ \\ ${ }^{1}$ Department of Mechanical Engineering, Dr. Navalar Nedunchezhiyan College of Engineering, Tholudur 606 303, India \\ ${ }^{2}$ Department of Mechanical Engineering, Thanthai Periyar Government Institute of Technology, Vellore 2, India \\ ${ }^{3}$ Department of Mechanical Engineering, UCSI University, North Wing, 56000 Kuala Lumpur, Malaysia
}

Correspondence should be addressed to V. Sathiyamoorthy; sathiyamoorthy01@gmail.com

Received 29 November 2014; Accepted 5 January 2015

Academic Editor: Venkatesh Jaganathan

Copyright (C) 2015 V. Sathiyamoorthy et al. This is an open access article distributed under the Creative Commons Attribution License, which permits unrestricted use, distribution, and reproduction in any medium, provided the original work is properly cited.

\begin{abstract}
Formation of spikes prevents achievement of the better material removal rate (MRR) and surface finish while using plain $\mathrm{NaNO}_{3}$ aqueous electrolyte in electrochemical machining (ECM) of die tool steel. Hence this research work attempts to minimize the formation of spikes in the selected workpiece of high carbon high chromium die tool steel using copper nanoparticles suspended in $\mathrm{NaNO}_{3}$ aqueous electrolyte, that is, nanofluid. The selected influencing parameters are applied voltage and electrolyte discharge rate with three levels and tool feed rate with four levels. Thirty-six experiments were designed using Design Expert 7.0 software and optimization was done using multiobjective genetic algorithm (MOGA). This tool identified the best possible combination for achieving the better MRR and surface roughness. The results reveal that voltage of $18 \mathrm{~V}$, tool feed rate of $0.54 \mathrm{~mm} / \mathrm{min}$, and nanofluid discharge rate of 12 lit/min would be the optimum values in ECM of HCHCr die tool steel. For checking the optimality obtained from the MOGA in MATLAB software, the maximum MRR of $375.78277 \mathrm{~mm}^{3} / \mathrm{min}$ and respective surface roughness Ra of $2.339779 \mu \mathrm{m}$ were predicted at applied voltage of $17.688986 \mathrm{~V}$, tool feed rate of $0.5399705 \mathrm{~mm} / \mathrm{min}$, and nanofluid discharge rate of $11.998816 \mathrm{lit} / \mathrm{min}$. Confirmatory tests showed that the actual performance at the optimum conditions was $361.214 \mathrm{~mm}^{3} / \mathrm{min}^{\mathrm{and}}$ $2.41 \mu \mathrm{m}$; the deviation from the predicted performance is less than $4 \%$ which proves the composite desirability of the developed models.
\end{abstract}

\section{Introduction}

Advanced high hardness materials have a high importance especially for the applications such as automotive, metal forming, die making, and aerospace industries. ECM is more suitable process to have excellent and precise machining of these hard materials. It is a technical alternate in the field of manufacturing process to machine steels and superalloys due to avoidance of thermal stresses on their microstructures and absence of tool wear during the machining process $[1,2]$. It is more appropriate one to machine a nonmachinable hard materials such as $\mathrm{HCHCr}$ die tool steel, AISI 202 Austenitic stainless steel, and superalloys $[3,4]$. The parameters of the ECM influencing the objectives of MRR and surface roughness are applied voltage, tool feed rate, and electrolyte discharge rate [5-7]. The electrolyte flows through the interelectrode gap (IEG) and the machining reaction is very appreciable when the value of IEG is small $[8,9]$. During the electrochemical machining, the formation of spikes, due to presence of passive layer formation, inconsistency of current density, and formation of gas at the IEG, prevent achievement of the better MRR and surface roughness. Hence this attempts to minimize the formation of spikes in the machined component by using copper nanoparticles suspended in $\mathrm{NaNO}_{3}$ aqueous electrolyte solution. In order to find out an optimal condition, multiobjective genetic algorithm (MOGA) has been applied in this research work.

\section{Experimental Setup}

The experiments were conducted using ECM setup as shown in Figure 1. The selected workpiece material $\mathrm{HCHCr}$ die steel with hardness of 67 in HRc scale was one of the poor machinability materials [10]. The complete chemical 


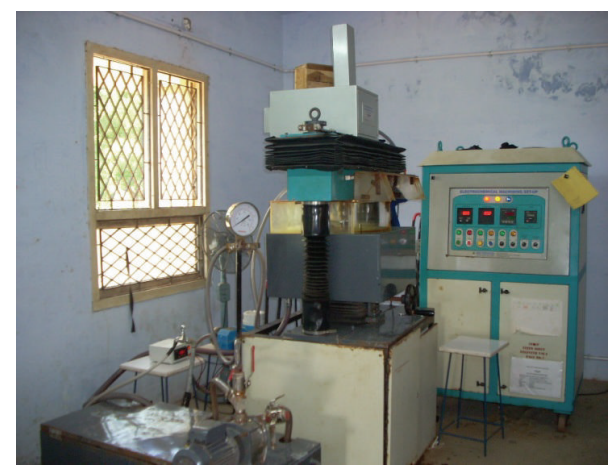

FIGURE 1: ECM setup.

TABLE 1: Chemical composition of HCHCr die tool steel.

\begin{tabular}{lccccccc}
\hline Element & $\mathrm{C}$ & $\mathrm{Cr}$ & $\mathrm{Mn}$ & $\mathrm{P}$ & $\mathrm{S}$ & $\mathrm{Fe}$ & $\mathrm{Si}$ \\
\hline $\mathrm{Wt} \%$ & 1.936 & 11.84 & 0.27 & 0.044 & 0.089 & 85.34 & 0.48 \\
\hline
\end{tabular}

composition of HCHCr die steel is presented in Table 1. The plain aqueous solution of $15 \% \mathrm{NaNO}_{3}$ and $40 \mathrm{~g}$ of $\mathrm{Cu}$ nanoparticles suspended in plain aqueous solution of $15 \%$ $\mathrm{NaNO}_{3}$ were selected as electrolytes in these experiments [11]. The electrolyte solution was completely analyzed using deluxe water and soil analysis kit, Model-191E. A digital flow meter with two-digit accuracy was employed to adjust the flow rate of electrolyte to the IEG. Copper was chosen for fabrication of tool due to high electrical conductivity. In the present work, the IEG is set to be $0.5 \mathrm{~mm}$ initially throughout the experimentation [12]. Material removal (MR) is the difference in the weight of the workpiece before and after machining. The accuracy of measurement is ensured using Sartorius electronic weighing machine with three-digit accuracy. Mitutoyo surface tester with a range of $0-150 \mu \mathrm{m}$ is used to measure surface roughness $(\mathrm{Ra})$ and the average of values observed in three different surfaces on the workpiece is computed in each experiment. The process parameters used in the complete experiment are presented in Table 2.

\section{Mathematical Modeling of Machining Parameters}

Design Expert 7.0 software is used to determine the relationship among the selected influencing parameters. Three levels have been selected for influencing parameters of the applied voltage, electrolyte discharge rate, and four levels selected for tool feed rate. It is possible to assess the main and interaction effects of different machining parameters in $\mathrm{L}_{36}$ array with most reasonable accuracy. A first-order experiment was performed to determine the magnitudes of the relative changes to the process parameters that would result in optimum MRR and surface roughness. It is obtained from the first-order experiments; copper nanoparticles suspended in aqueous $\mathrm{NaNO}_{3}$ electrolyte significantly improve the MRR and surface roughness compared to plain aqueous $\mathrm{NaNO}_{3}$ electrolyte. Subsequently, a second-order central composite design was selected to identify the optimum conditions which

TABle 2: Process parameters.

Applied voltage (V)

Interelectrode gap $(\mathrm{mm})$

Tool feed rate $(\mathrm{mm} / \mathrm{min})$

Electrolyte discharge rate (lit/min)

Selected electrolyte

Tool-electrode condition

Electrolyte temperature

range $\left({ }^{\circ} \mathrm{C}\right)$

Workpiece material with its hardness

Machining time (min)
12,15 , and 18

0.1

$0.1,0.21,0.32$, and 0.54

8,10 , and 12

$15 \% \mathrm{NaNO}_{3}$ aqueous solution $40 \mathrm{~g}$ copper nanoparticles suspended in $15 \% \mathrm{NaNO}_{3}$ aqueous solution

Stationary

$30^{\circ}-40^{\circ}$

HCHCr die steel-67 HRc 3

turn into the higher MRR and finest surface roughness. The general form of second-order polynomial mathematical model applied to investigate the parametric effects of ECM is

$$
Y u=b_{0}+\sum_{i=1}^{n} b_{i} x_{i u}+\sum_{i=1}^{n} b_{i i} x_{i u 2}^{2}+\sum_{i<j}^{n} b_{i j} x_{i u} x_{j u},
$$

where $Y u$ is the response and terms $b_{0}, b_{i}$, and so forth are the second-order regression coefficients. Various sets of parametric combinations results are obtained by conducting a series of experiments. The respective mathematical models representing MRR in view of plain aqueous $\mathrm{NaNO}_{3}$ and $\mathrm{Cu}$ nanoparticles suspended in plain aqueous $\mathrm{NaNO}_{3}$ electrolyte are computed as

$$
\begin{aligned}
Y u(\mathrm{MRR})= & -17.794-22.942 X_{1}-340.754 X_{2} \\
& +54.275 X_{3}+6.834 X_{1} X_{2}-2.018 X_{1} X_{3} \\
& +4.178 X_{2} X_{3}+1.642 X_{1}^{2} \\
& +280.163 X_{2}{ }^{2}-0.682 X_{3}^{2}, \\
Y u_{1}(\mathrm{MRR})= & -603.747+117.441 X_{1}-170.503 X_{2} \\
& -48.750 X_{3}+12.903 X_{1} X_{2}-0.215 X_{1} X_{3} \\
& +11.491 X_{2} X_{3}-3.442 X_{1}{ }^{2} \\
& +98.005 X_{2}{ }^{2}+3.305 X_{3}{ }^{2},
\end{aligned}
$$

where $Y u(\mathrm{MRR}), Y u_{1}(\mathrm{MRR}), X_{1}, X_{2}$, and $X_{3}$ represent MRR of plain aqueous $\mathrm{NaNO}_{3}, \mathrm{Cu}$ nanoparticles suspended in plain aqueous $\mathrm{NaNO}_{3}$, applied voltage, tool feed rate, and electrolyte discharge rate, respectively. The developed mathematical model will enable improvement of the performance of ECM while machining $\mathrm{HCHCr}$ die steel. The degree of fitness of the developed mathematical model is confirmed through ANOVA test. The coefficient of determination $R^{2}$ for MRR in terms of aqueous $\mathrm{NaNO}_{3}$ and $\mathrm{Cu}$ nanoparticles suspended in aqueous $\mathrm{NaNO}_{3}$ solutions were $90.97 \%$ and 
93.45\%, respectively, which confirms the accuracy of fitness of the mathematical model.

The respective mathematical models representing surface roughness in view of plain aqueous $\mathrm{NaNO}_{3}$ and $\mathrm{Cu}$ nanoparticles suspended in plain aqueous $\mathrm{NaNO}_{3}$ electrolytes are computed as

$$
\begin{aligned}
Y u(\mathrm{SR})= & -24.807+1.252 X_{1}+6.630 X_{2}+3.024 X_{3} \\
& -0.239 X_{1} X_{2}-0.070 X_{1} X_{3}-0.478 X_{2} X_{3} \\
& -0.012 X_{1}{ }^{2}+6.655 X_{2}{ }^{2}-0.101 X_{3}{ }^{2}, \\
Y u_{1}(\mathrm{SR})= & -27.358+3.022 X_{1}+9.793 X_{2}+1.488 X_{3} \\
& -6.251 X_{1} X_{2}-0.072 X_{1} X_{3}-0.487 X_{2} X_{3} \\
& -0.0740 X_{1}{ }^{2}+9.506 X_{2}{ }^{2}-0.022 X_{3}{ }^{2},
\end{aligned}
$$

where $Y u(\mathrm{SR}), Y u_{1}(\mathrm{SR}), X_{1}, X_{2}$, and $X_{3}$ represent surface roughness of aqueous $\mathrm{NaNO}_{3}, \mathrm{Cu}$ nanoparticles suspended in aqueous $\mathrm{NaNO}_{3}$ electrolyte, applied voltage, tool feed rate, and electrolyte discharge rate, respectively. The coefficient of determination $R^{2}$ obtained from ANNOVA for surface roughness in terms of aqueous $\mathrm{NaNO}_{3}$ and $\mathrm{Cu}$ nanoparticles suspended in aqueous $\mathrm{NaNO}_{3}$ electrolytes were $92.55 \%$ and $96.98 \%$, respectively, which confirms the fitness of the mathematical model.

\section{Optimization Using Multiobjective Genetic Algorithm in MATLAB}

Evolutionary algorithms seem mainly suitable to solve multiobjective optimization problems, because they deal simultaneously with a set of possible solutions (population). The traditional mathematical programming techniques need a series of separate runs to find the optimum solution for multiobjective problems. Contrarily, this method allows finding several members of the optimal set in a single run of the algorithm. In this research work multiobjective genetic algorithm toolbox from the MATLAB software is chosen for optimizing the selected objectives, maximizing the MRR and minimizing the surface roughness. The ability of GA to simultaneously search different regions of a solution space makes it possible to find a diverse set of solutions for difficult problems with nonconvex, discontinuous, and multimodal solutions spaces [13-15].

\section{Analysis of the Influence of Parametric on the MRR and Surface Roughness for Aqueous $\mathrm{NaNO}_{3}$ Electrolyte}

The mathematical models developed using RSM and presented in (2) and (4) were used in GA toolbox as fitness functions. The limitation for the optimization is given as follows:

$$
6 \leq x_{1} \geq 12, \quad 3 \leq x_{2} \geq 9, \quad 3 \leq x_{3} \geq 9 .
$$

The GA generally includes three fundamental genetic operations of selection, namely, population, crossover, and

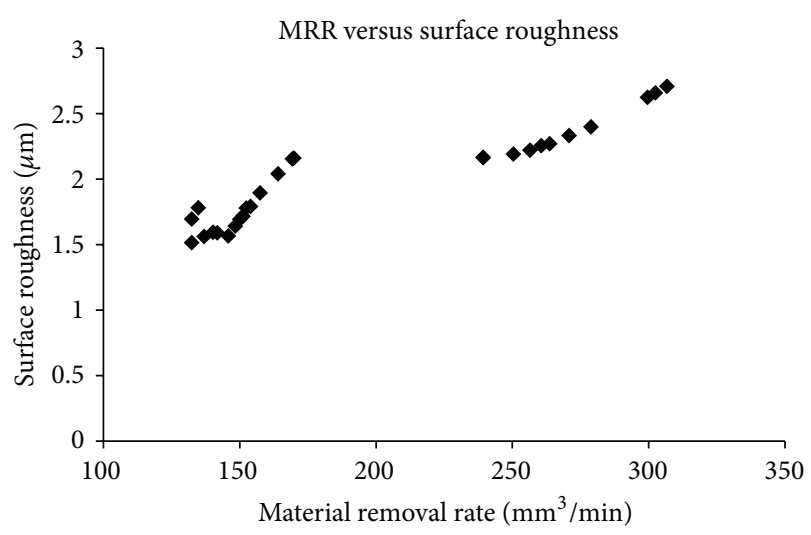

Figure 2: Optimal parameters of aqueous $\mathrm{NaNO}_{3}$ solution from GA.

mutation. These operations are used to modify the chosen solutions and select the most appropriate offspring to pass on to succeeding generations. The following parameters were considered during optimization using GA multiobjective tool. Population size $=225$, crossover fraction $=0.8$, mutation function $=$ constraint dependent, crossover function $=$ scattered, and number of iterations $=188$.

Upon applying objective functions in GA tool, the results were obtained as tabulated in Table 3 and Figure 2.

The response plot shows the effects of applied voltage, tool feed rate, and electrolyte discharge rate on MRR and surface roughness of $\mathrm{HCHCr}$ die tool steel. MRR increases at higher voltage with the increase of tool feed rate and higher flow of electrolyte discharge rate at a mean time surface roughness slightly increased. A maximum MRR $306.69449 \mathrm{~mm}^{3} / \mathrm{min}$ was achieved under tool feed rate of $0.5399502 \mathrm{~mm} / \mathrm{min}$, $11.97976 \mathrm{lit} / \mathrm{min}$ of electrolyte discharge rate, and applied voltage of $17.995820 \mathrm{~V}$. A minimum SR value of $1.513575 \mu \mathrm{m}$ was observed at $12 \mathrm{~V}, 0.1100281 \mathrm{~mm} / \mathrm{min}$ of tool feed rate, and $8.134412 \mathrm{lit} / \mathrm{min}$ of electrolyte discharge rate.

\section{Analysis of the Influence of Parametric on the MRR and Surface Roughness for Cu Nanoparticles Suspended in Aqueous $\mathrm{NaNO}_{3}$ Electrolyte}

Table 4 and Figure 3 present the results from GA for $\mathrm{Cu}$ nanoparticles suspended in aqueous $\mathrm{NaNO}_{3}$ electrolyte. MRR increases at higher values of electrolyte discharge rate and tool feed rate. The surface roughness decreases when the electrolyte discharge rate and tool feed rate are decreased. A maximum value of MRR $375.78277 \mathrm{~mm}^{3} / \mathrm{min}$ was obtained under $17.688986 \mathrm{~V}, 0.5399705 \mathrm{~mm} / \mathrm{min}$ tool feed rate, and $11.998816 \mathrm{lit} / \mathrm{min}$ electrolyte discharge rate conditions. The minimum surface finish of $1.4973965 \mu \mathrm{m}$ was observed at $17.999473 \mathrm{~V}, 0.2344207 \mathrm{~mm} / \mathrm{min}$ tool feed rate, and $11.997052 \mathrm{lit} / \mathrm{min}$ electrolyte discharge rate condition.

It is obvious that the optimum search can be obtained based on the developed second-order response, surface equations for correlating the various process variable effects with 
TABLE 3: Process decision variables along with optimized response from GA for aqueous $\mathrm{NaNO}_{3}$.

\begin{tabular}{|c|c|c|c|c|c|}
\hline Sl. number & Voltage (V) & Feed rate $(\mathrm{mm} / \mathrm{min})$ & Discharge rate (lit/min) & $\operatorname{MRR}\left(\mathrm{mm}^{3} / \mathrm{min}\right)$ & Surface roughness (micron) \\
\hline 1 & 12 & 0.1100281 & 8.134412 & 132.46309 & 1.513575 \\
\hline 2 & 12.030211 & 0.1104329 & 9.087866 & 152.49089 & 1.777581 \\
\hline 3 & 12.014045 & 0.1039534 & 10.04123 & 169.34532 & 2.152654 \\
\hline 4 & 17.995146 & 0.5265484 & 11.98002 & 302.51291 & 2.656720 \\
\hline 5 & 12.000245 & 0.1005786 & 9.147932 & 153.98288 & 1.791250 \\
\hline 6 & 17.991590 & 0.3675932 & 11.97936 & 260.68191 & 2.254694 \\
\hline 7 & 12.006746 & 0.2003393 & 8.234414 & 137.00311 & 1.560310 \\
\hline 8 & 12.008757 & 0.1019808 & 10.06793 & 169.87964 & 2.159093 \\
\hline 9 & 17.989152 & 0.3175749 & 11.99351 & 250.47074 & 2.189059 \\
\hline 10 & 12.000737 & 0.1004096 & 9.719882 & 164.05383 & 2.038806 \\
\hline 11 & 12.009474 & 0.2017167 & 8.488291 & 141.77756 & 1.587574 \\
\hline 12 & 17.994398 & 0.5169848 & 11.97913 & 299.58104 & 2.623729 \\
\hline 13 & 17.985153 & 0.2530979 & 11.99503 & 239.31519 & 2.164326 \\
\hline 14 & 17.988464 & 0.3482414 & 11.99409 & 256.55458 & 2.219778 \\
\hline 15 & 12.012065 & 0.1043002 & 8.710513 & 145.82497 & 1.564311 \\
\hline 16 & 17.990082 & 0.4115904 & 11.98257 & 270.80421 & 2.330752 \\
\hline 17 & 17.986068 & 0.3813624 & 11.99307 & 263.68107 & 2.268322 \\
\hline 18 & 12.004311 & 0.1041213 & 8.848672 & 148.38304 & 1.639634 \\
\hline 19 & 12.000057 & 0.2000266 & 8.109496 & 134.59464 & 1.771653 \\
\hline 20 & 12.015943 & 0.1038107 & 8.938570 & 150.04776 & 1.691262 \\
\hline 21 & 17.988003 & 0.4437773 & 11.99324 & 278.90557 & 2.397192 \\
\hline 22 & 12.001201 & 0.1004778 & 8.995683 & 151.23304 & 1.714381 \\
\hline 23 & 12 & 0.2 & 8.874121 & 132.46309 & 1.693575 \\
\hline 24 & 17.995820 & 0.5399502 & 11.97976 & 306.69449 & 2.706127 \\
\hline 25 & 12.007139 & 0.1076954 & 8.422892 & 140.26985 & 1.592297 \\
\hline 26 & 17.985182 & 0.2532877 & 11.99497 & 239.34474 & 2.164350 \\
\hline 27 & 12.013497 & 0.1039507 & 9.351800 & 157.47043 & 1.892639 \\
\hline
\end{tabular}

TABLE 4: Process decision variables along with optimized response from GA for $\mathrm{Cu}$ nanoparticles suspended in aqueous $\mathrm{NaNO}_{3}$ electrolyte.

\begin{tabular}{lccccc}
\hline Sl. number & Voltage $(\mathrm{V})$ & Feed rate $(\mathrm{mm} / \mathrm{min})$ & Discharge rate $(\mathrm{lit} / \mathrm{min})$ & MRR $\left(\mathrm{mm}^{3} / \mathrm{min}\right)$ & Surface roughness $(\mathrm{micron})$ \\
\hline 1 & 17.688986 & 0.5399705 & 11.998816 & 375.78277 & 2.339779 \\
2 & 17.999473 & 0.2344207 & 11.997052 & 291.21779 & 1.4973965 \\
3 & 17.982536 & 0.3619794 & 11.990806 & 324.01735 & 1.6773238 \\
4 & 17.812326 & 0.5399910 & 11.998295 & 375.72198 & 2.3501116 \\
5 & 17.974140 & 0.4719105 & 11.991869 & 354.97140 & 2.0744706 \\
6 & 17.986820 & 0.3385383 & 11.997917 & 317.93316 & 1.6169858 \\
7 & 17.995289 & 0.2727332 & 11.99707 & 300.7935 & 1.5171501 \\
8 & 17.981729 & 0.4545162 & 11.997314 & 350.07699 & 1.9885303 \\
9 & 17.970973 & 0.5100869 & 11.997924 & 366.45561 & 2.2630915 \\
10 & 17.991024 & 0.3212817 & 11.997223 & 313.33371 & 1.5817197 \\
11 & 17.957900 & 0.5030484 & 11.997998 & 364.38746 & 2.2357070 \\
12 & 17.955889 & 0.4263774 & 11.997138 & 342.11877 & 1.8942504 \\
13 & 17.896183 & 0.5389892 & 11.998794 & 375.34015 & 2.3713213 \\
14 & 17.917751 & 0.5150918 & 11.998277 & 368.07683 & 2.3296118 \\
15 & 17.960839 & 0.4768214 & 11.996795 & 356.60081 & 2.1042235 \\
16 & 17.913224 & 0.5219700 & 11.998223 & 370.14799 & 2.3709887 \\
17 & 17.963386 & 0.4965703 & 11.997834 & 362.44458 & 2.1984027 \\
18 & 17.997099 & 0.2431022 & 11.997066 & 293.37153 & 1.5003086 \\
19 & 17.991022 & 0.3212817 & 11.997223 & 313.33371 & 1.5817197 \\
\hline
\end{tabular}


TABLE 5: Error between optimum values from GA and confirmation test value for maximum MRR.

\begin{tabular}{|c|c|c|c|c|c|c|c|}
\hline \multirow[b]{2}{*}{ Sl. number } & \multirow[b]{2}{*}{ Electrolyte } & \multicolumn{2}{|c|}{ Obtained from GA } & \multicolumn{2}{|c|}{ Confirmation test } & \multicolumn{2}{|c|}{ Error } \\
\hline & & $\begin{array}{c}\mathrm{MRR} \\
\mathrm{mm}^{3} / \mathrm{min}\end{array}$ & $\begin{array}{c}\mathrm{SR} \\
\mu \mathrm{m}\end{array}$ & $\begin{array}{c}\mathrm{MRR} \\
\mathrm{mm}^{3} / \mathrm{min}\end{array}$ & $\begin{array}{c}\mathrm{SR} \\
\mu \mathrm{m}\end{array}$ & $\begin{array}{c}\text { MRR } \\
\%\end{array}$ & $\begin{array}{c}\text { SR } \\
\%\end{array}$ \\
\hline 1 & Aqueous $\mathrm{NaNO}_{3}$ & 306.69449 & 2.706127 & 294.012 & 2.82 & 4.13 & 4.25 \\
\hline 2 & $\begin{array}{c}\mathrm{Cu} \text { nanoparticles } \\
\text { suspended in } \\
\text { aqueous } \\
\mathrm{NaNO}_{3} \\
\end{array}$ & 375.78277 & 2.339779 & 361.214 & 2.41 & 3.87 & 3.31 \\
\hline
\end{tabular}

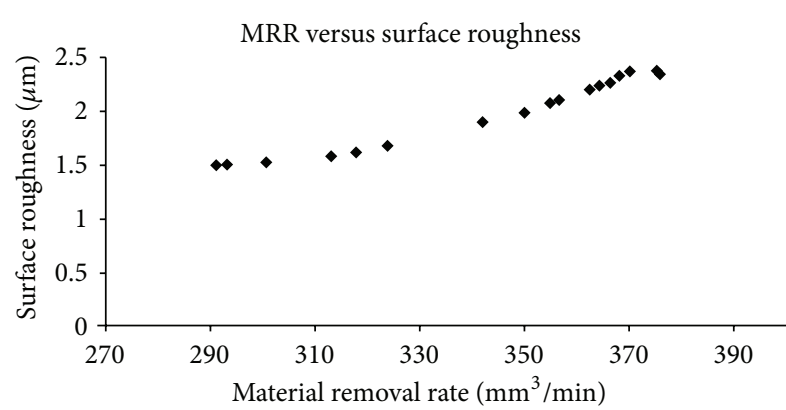

FIGURE 3: Optimal parameters of $\mathrm{Cu}$ nanoparticles suspended in aqueous $\mathrm{NaNO}_{3}$ solution from multiobjective GA.

the MRR and surface roughness. The optimal combination of various process variables thus obtained for achieving controlled electrochemical machining of the workpieces is found to be within the bounds of the mathematical model.

\section{Confirmation Test}

The confirmatory experiments were further conducted for the optimal parameters obtained from the MATLAB multiobjective GA tool. The error between optimum values from GA and the confirmation test was derived by considering the serial number 24 and serial number 1 from Tables 3 and 4, respectively, at the condition of maximum MRR and is shown in Table 5.

\section{Conclusions}

This work employs a multiobjective genetic algorithm (GA) tool to optimize influencing parameters of ECM to maximize the MRR and minimize surface roughness of $\mathrm{HCHCr}$ die steel. Based on the experimental results, the following conclusions are drawn.

(1) Material removal rate increases linearly with applied voltage and nonlinearly increases with tool feed rate. Surface roughness decreases with increase in the applied voltage and all tool feed rates. Mathematical models for MRR and surface roughness have been developed by Design Expert 7.0 software. It is useful for analyzing the influence of the various process parameters for achieving better MRR and surface roughness of $\mathrm{HCHCr}$ die tool steel.
(2) Genetic algorithm (GA) tool optimizes the range of influencing parameters in order to obtain a maximum MRR and minimum surface roughness. The experimental results reveal that applied voltage of $18 \mathrm{~V}$, tool feed rate of $0.54 \mathrm{~mm} / \mathrm{min}$, and electrolyte discharge rate of $12 \mathrm{lit} / \mathrm{min}$ would be the optimum values in ECM of HCHCr die tool steel under copper nanoparticles suspended in aqueous $\mathrm{NaNO}_{3}$ electrolyte solution machining condition.

(3) For checking the optimality obtained from the multiobjective GA in MATLAB, MRR of $375.78277 \mathrm{~mm}^{3}$ / min and surface roughness $\mathrm{Ra}$ of $2.339779 \mu \mathrm{m}$ were predicted at applied voltage of $18 \mathrm{~V}$, tool feed rate of $0.54 \mathrm{~mm} / \mathrm{min}$, and electrolyte discharge rate of $11.99 \mathrm{lit} / \mathrm{min}$.

(4) Confirmatory tests showed that the actual performance at the optimum conditions was $361.214 \mathrm{~mm}^{3}$ / min and $2.41 \mu \mathrm{m}$; a deviation from the predicted performance is less than $4 \%$ at maximum material removal rate condition which has proven the composite desirability of the developed models for MRR and surface roughness under copper nanoparticles suspended in aqueous $\mathrm{NaNO}_{3}$ electrolyte solution machining condition. Aqueous $\mathrm{NaNO}_{3}$ electrolyte solutions performance is poor comparing to copper nanoparticles suspended in aqueous $\mathrm{NaNO}_{3}$ electrolyte solution.

(5) Comparing the predicted performance of aqueous $\mathrm{NaNO}_{3}$ and copper nanoparticles suspended in aqueous $\mathrm{NaNO}_{3}$ electrolyte solutions on experimentally and mathematically, copper nanoparticles suspended in aqueous $\mathrm{NaNO}_{3}$ electrolyte solution performs better for MRR and surface roughness on $\mathrm{HCHCr}$ die tool steel.

\section{Conflict of Interests}

The authors declare that there is no conflict of interests regarding the publication of this paper.

\section{References}

[1] S. H. Ahn, S. H. Ryu, D. K. Choi, and C. N. Chu, "Electrochemical micro drilling using ultra short pulses," Precision Engineering, vol. 28, no. 2, pp. 129-134, 2004. 
[2] R. Goswami, V. Chaturvedi, and R. Chouhan, "Optimization of electrochemical machining process parameters using Taguchi approach," International Journal of Engineering Science and Technology, vol. 5, no. 5, pp. 999-1006, 2013.

[3] T. Sekar and R. Marappan, "Experimental investigations into the influencing parameters of electrochemical machining of AISI 202," Journal of Advanced Manufacturing Systems, vol. 7, no. 2, pp. 337-343, 2008.

[4] L. Tang and Y.-F. Guo, "Experimental study of special purpose stainless steel on electrochemical machining of electrolyte composition," Materials and Manufacturing Processes, vol. 28, no. 4, pp. 457-462, 2013.

[5] Z. Li and H. Ji, "Machining accuracy prediction of aeroengine blade in electrochemical machining based on BP neural network," in Proceedings of the International Workshop on Information Security and Application, pp. 244-247, 2009.

[6] M. Wang, W. Peng, C. Yao, and Q. Zhang, "Electrochemical machining of the spiral internal turbulator," International Journal of Advanced Manufacturing Technology, vol. 49, no. 9-12, pp. 969-973, 2010.

[7] A. Hasçalik and U. Çaydaş, "A comparative study of surface integrity of Ti-6Al-4V alloy machined by EDM and AECG," Journal of Materials Processing Technology, vol. 190, no. 1-3, pp. 173-180, 2007.

[8] Z. Brusilovski, "Adjustment and readjustment of electrochemical machines and control of the process parameters in machining shaped surfaces," Journal of Materials Processing Technology, vol. 196, no. 1-3, pp. 311-320, 2008.

[9] J. Kozak, M. Chuchro, A. Ruszaj, and K. Karbowski, "The Computer aided simulation of electrochemical process with universal spherical electrodes when machining sculptured surfaces," Journal of Materials Processing Technology, vol. 107, no. 1-3, pp. 283-287, 2000.

[10] K. G. Judal and V. Yadava, "Cylindrical electrochemical magnetic abrasive machining of AISI-304 stainless steel," Materials and Manufacturing Processes, vol. 28, no. 4, pp. 449-456, 2013.

[11] P. C. Tan and S. H. Yeo, "Investigation of recast layers generated by a powder-mixed dielectric micro electrical discharge machining processg," Proceedings of the Institution of Mechanical Engineers, Part B: Journal of Engineering Manufacture, vol. 225, no. 7, pp. 1051-1062, 2011.

[12] B. Bhattacharyya, M. Malapati, and J. Munda, "Experimental study on electrochemical micromachining," Journal of Materials Processing Technology, vol. 169, no. 3, pp. 485-492, 2005.

[13] D. F. Jones, S. K. Mirrazavi, and M. Tamiz, "Multi-objective meta-heuristics: an overview of the current state-of-the-art," European Journal of Operational Research, vol. 137, no. 1, pp. 1-9, 2002.

[14] K. Tang, J. Yang, H. Chen, and S. Gao, "Improved genetic algorithm for nonlinear programming problems," Journal of Systems Engineering and Electronics, vol. 22, no. 3, pp. 540-546, 2011.

[15] R. Mukherjee and S. Chakraborty, "Selection of the optimal electrochemical machining process parameters using biogeography-based optimization algorithm," The International Journal of Advanced Manufacturing Technology, vol. 64, no. 5-8, pp. 781-791, 2013. 

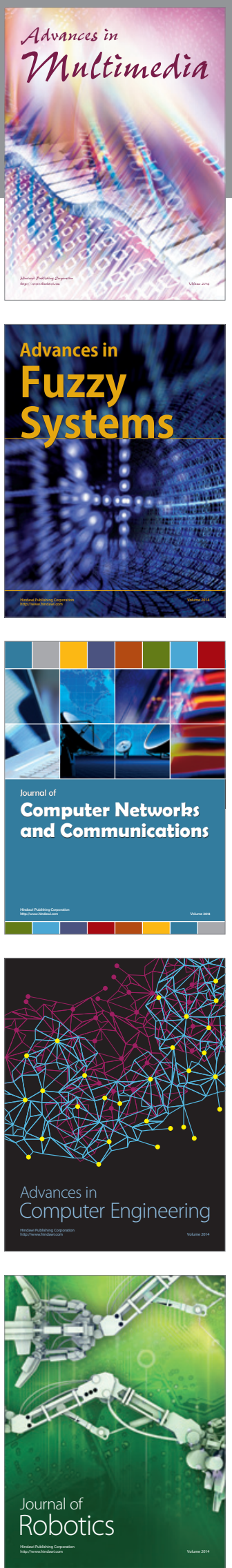

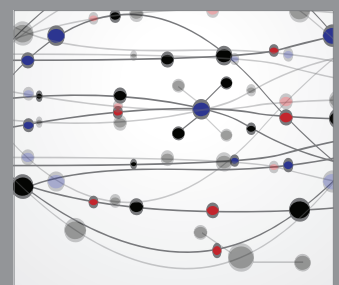

The Scientific World Journal
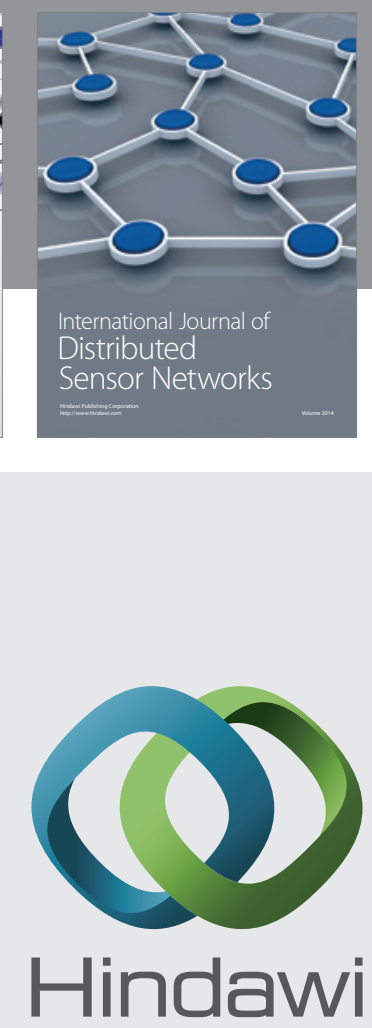

Submit your manuscripts at

http://www.hindawi.com
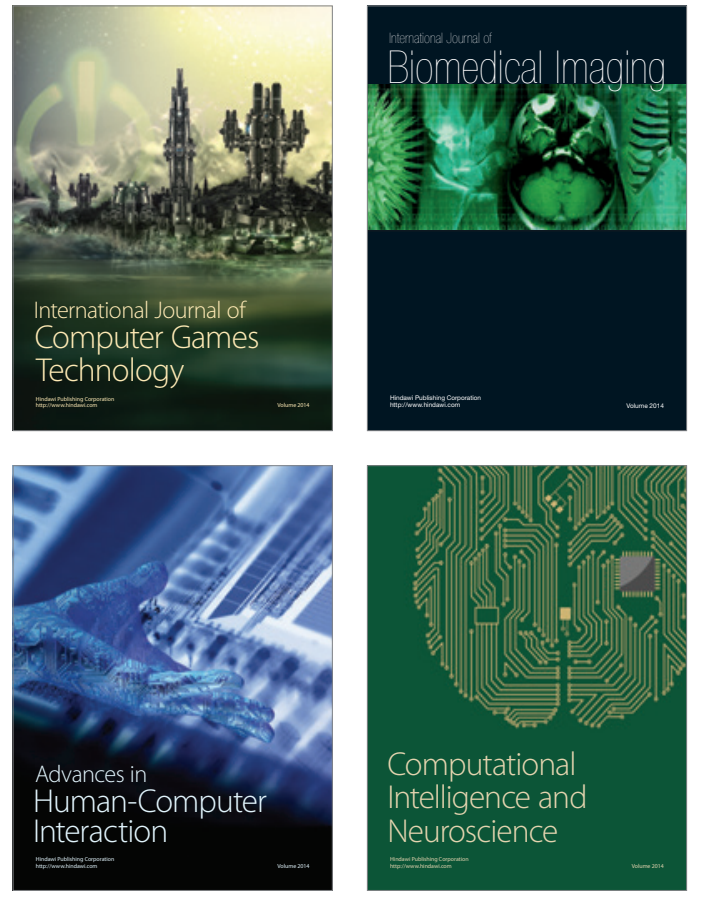
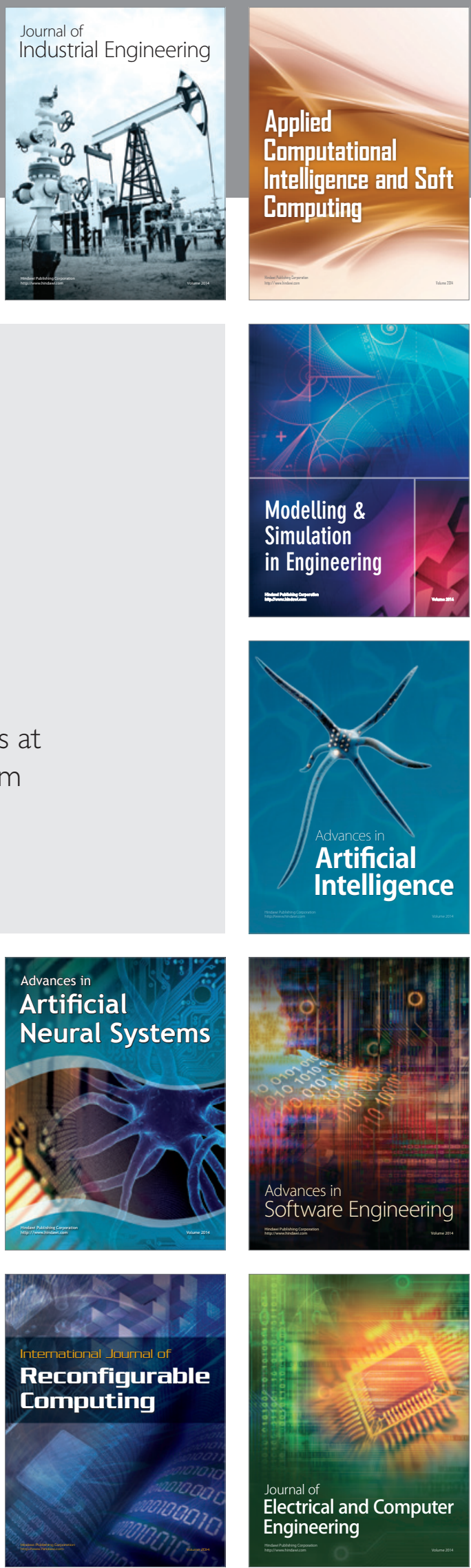